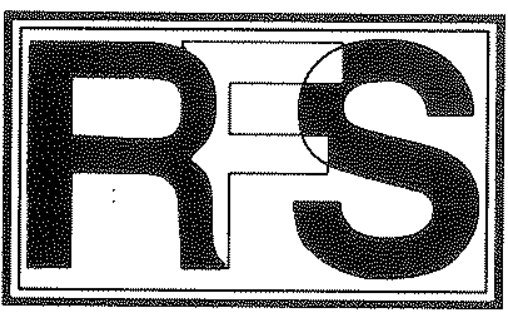

Revisia de Fomento Social, 49 (1994), 263+283

\title{
La construcción jurídica del voluntariado social
}

Reflexiones sobre voluntariado y derecho a propósito de la ley aragonesa 9/1992, de 7 de octubre

El voluntariado constituye una de las manifestaciones en la denominada crisis del Estado de Bienestar. Este fenómeno en el que subyace una fuerte dosis de altruismo y de respuesta de la sociedad civil ante diversas necesidades sociales contrasta con el individualismo y el consumismo imperante. En el presente trabajo se pretende aportaralgunas reflexiones que ayuden allector a comprendermejor esta realidad sobre todoen sus dimensiones e implicaciones socio-políticas y jurídicas. Para ello, muchas de sus ideas se fundamentan en el apoyo normativo que recientemente ha prestado a esta figura la ley Aragonesa $9 / 1992$ de 7 de octubre.

- Andrés GARCIA INDA y Ma Luisa CASARES VILLANUEVA(*)-

(*) Andrés Garcia Inda es profesor ayudante de Filosofia del derecho, moral y política en la Universidad de Zaragoza. $\mathrm{M}^{9}$ Luisa Casares es juez. 


\section{Del fenómeno social del voluntariado al fenómeno del voluntariado social}

El voluntariado como fenómeno social, y con sus diversas acepciones y matices (servicio voluntario, voluntariado, accion voluntaria...), se ha convertido útimamente en objeto de atención, análisis y estudio desde diferentes perspectivas y planteamientos. Por ejemplo, Juan Pablo II en su encíclica Centesimus annus considera que «es digno de mención especial el fenómeno del voluntariado, que la Iglesia favorece y promueve, solicitando la colaboración de todos para sostenerlo y animarlo en sus iniciativas» 1 . $O$ desde otro punte de vista, Pietro Barcellona ha hablado del voluntariado en la línea de «la refundación de una esfera social de relaciones interpersonales y sociales sustraída a la lógica perversa de la institucionalización de las necesidades humanas $\aleph^{2}$. Otras reflexiones se han llegado a formular en la perspectiva de una atractiva cultura 0 ética (en su sentido amplio) del voluntariado (de la gratuidad) que es toda una propuesta de iransformación social ${ }^{3}$.

De forma que desde diferentes planteamientos socio-políticos, éticos e

(1) Juan Pablo I, Centesimus annus, n. 49. El contex to de esa cita es el capitulo $V$ de la enciclica tifulado «Estado y Cultura» y, más precisamente, las teflexiones sobre el papel del Estado en la economía y en la lógica asistencial, atendiendo al viejo principio de subsidiariedad según el cual «Una estructura de orden superior no debe interferir en la vida in tema de un grupo social de orden inferior privándola de sus competencias, sino que más bien debe sostenerla en caso de necesidad y ayudarla a coordinar su acción con la de los demás componentes sociales, con miras al bien común» (n. 48). Sobre ello vid. Juan María LABOA (ed.), Solidaridad y subsidiariedad en la sociedad española, Madrid, Univ. Pontificia Comillas, 1993.

(2) BARCELLONA, P. (1992), Postmodernidad y comunidad, Madrid, Trotta, pág, 108.

(3) Cfr. Jonquín GARCIA ROCA, «La cultura del voluntariado», en Sal Terrae vol. 77, junio $1989 / 6$, págs. 449-461. La bibliografía sobre el voluntariado en nuestro país también se há hecho abundante ( $y$ en muchos casos depende del campo o áfea del trabajo y la participación social en que se mueve la acción voluntaria). Entre los trabajos más importantes y accesibles estarían los siguientes volúmenes colectivos: Voluntariado social: apuntes y propuestas, Madrid, Ed. Popular, 1986; Organizaciones voluntariase intervención social, Madrid, Acebo, 1989; El voluntariado en la acción socioculturral, Madrid, Ed. Popular, 1990; Coordinación de la acción voluntaria, Madrid, Acebo, 1991; El voluntariado, Madrid, Ed. Popular, 1993. También las revistas: Documenación Social, sobretodo núms, 64 (1986), 71 (1988), 80 (1990); y Sal Terrae vol. 77 (1989/6), entre otros trabajos. Y por supuesto los diferentes cuadernos y materiales de la «Plataforma para la Promoción del Voluntariado en España» (a partir de ahora PPVE). 
incluso religiosos, y desde diversas opticas ideologicas parece existir una apuesta por un fenómeno social que, por otro lado, existía hacía tiempo de una u otra forma. Pero no tal como se ha venido a considerar y en las condiciones politicas y sociales en las que se ha venido a considerar. Ya que la importancia de las discusiones sobre esta forma y formula de trabajo, acción y participación social se ven subrayadas por enmarcarse dentro de la discusión sobre la llamada crisis del Estado del Bienestar, asi como sobre las relaciones que en esa crisis mantienen los diferentes sectores del sistema social, es decir, lo que de forma más simple se ha presentado como la relación Estado-Sociedad civil. Y si ha cobrado tal importancia la reflexión sobre el fenómeno social en esa relación es además porque éste ha cuajado como forma de organización en determinadas instituciones (fundamentalmente de trabajo y acción social), y en organizaciones dedicadas precisamente a canalizar y promover el trabajo voluntario como es en nuestro país la Plataforma para la Promoción del Voluntariado en Españat.

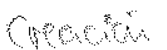

Dicha Plataforma, por otro lado, se creó a raúz de una Recomendación del Comité de Ministros del Consejo de Europa R. (85)9 de 21 de junio de 1985, sobre el trabajo voluntario en actividades de Bienestar Social. que instaba a los Estados miembros a reconocer «el papel, las características y el valor del trabajo voluntatio realizado de manera desinteresada por personas que por su propia voluntad participan en el bienestar social», así como a tomar «todas las medidas apropiadas a fin de definir y mejorar las modalidades de tal trabajo». Medidas que se proponían no sólo con carácter general sino también de forma especifica en cuanto a las organizaciones (respeto de su libertad de actuación, colaboración con las entidades de voluntarios, facilidades fiscales, apoyo material, estímulo...) y a los propios voluntarios (flexibilizar fórmulas legales, estímulo y formación, derechos del voluntario...). Junto a dicha Recomendación encontramos otros documentos carentes también de carácter normativo propiamente dicho pero con un importante valor jurídico-político en sentido amplio (como la Resolución de 19 de febrero de 1986 de la Asamblea General de Naciones Unidas sobre el Día Internacional del Volantario por un Desarrollo Económi-

(4) Cfr. ¿Qué es la plataforma?, «Cuademos de la Plataforma» № 1, Madrid, PPVE. A nivel comunitario existe el Comité de Coordinación del Voluntariado de los países de la Comunidad Europea, Volonteurope, fundado en 1980. 
co y Social, 0 , más político y menos jurídico todavía, la Carta europea para los voluntarios, propuesta por la organizacion Volonteurope), y otros con valor propiamente jurídico, normativo, que han contribuido al desarrollo y consolidación de lo que conocemos como voluntariado.

Entre los textos propiamente normativos, la Ley 13/1982, de 7 de abril de Integración Social de Minusválidos (B.O.E. 30-IV-1982), recogía de forma expresa y por primera vez en nuestro derecho una referencia al voluntariado en su artículo 64 , al decir que

«El Estado fomentará la colaboración del voluntariado en la atención de los disminuidos, promoviendo la constitución y funcionamiento de instituciones sin fin de lucro que agrupen a personas interesadas en esta actividad, a fin de que puedan colaborar con los profesionales en la realización de actuaciones de carácter vocacional en favor de aquéllos».

Y más tarde diversas leyes autonómicas han venido a reconocer (como decía la recomendación del Consejo de Europa) o regular esa figura del voluntariado, apoyándose en las competencias que en materia de asistencia y bienestar social les atribuye la Constitución y los respectivos Estatutos de Autonomía ${ }^{5}$.

Entre esas leyes, por ejemplo, está la de la Comunidad Autónoma de Aragón: Ley 9/1992, de 7 de octubre, del Voluntariado Social (B.O.E. 3-XI-1992), que trata de ofrecer, según señala el preámbulo un instrumento normativo «mucho más completo» que el contenido en otras nomativas autonómicas o en el precedente de la Ley estatal de Integración Social de Minusválidos, cuya fragmentariedad reside sobre todo en el hecho de reducirse a elaborar una noción de voluntariado y hacer un compromiso de apoyo y de regulación del mismo. Así lo manifiesta dicha Ley de la Comunidad Autónoma de Aragón en el preámbulo. La fragmentariedad o carácter incompleto de dichas normas, sin embargo, no les resta importancia. Por el contrario, tiene una cierta trascendencia, como veremos a continuación, por lo que hace a la eficacia simbólica del control jurídico.

(5) Para un inventario normativo del voluntariado (aunque pendiente de actualizar) y un planteamiento básico de sta problemática jurídica, vid. Angel FERNÁNDEZ PAMPILLON, Cuestiones juridicas del voluntariado, «Cuadernos de la Plataforma» $N^{*} 10$, Madrid, PPVE, 1990. 
La ley aragonesa está compuesta de dieciséis anículos agrupados en cinco títulos y diversas disposiciones adicionales y finales que abren la puerta a un posible desarrollo reglamentario posterior. A grandes rasgos, podemos describir su contenido partiendo de esos cinco títulos de la ley: disposiciones generales, competencias, estatuto del voluntariado social, programas y proyectos del voluntariado social y fomento, control y participación. Así, el lítulo I (arts. 1-5) plantea la noción de voluntariado y actuación voluntaria y dice qué entidades pueden realizar programas de accion social voluntaria, estableciendo los principios básicos de actuación del voluntariado social y los diversos campos a los que se dirigirán dichos programas de actuacion de voluntariado. El título II (que recoge únicamente el art. 6) fija las competencias de la Diputación General de Aragón, unas reservadas y otras compartidas con las Corporaciones Locales de la Comunidad Autónoma, en cuanto a inspección, capacidad de fijar las condiciones que debe reunir un proyecto de voluntariado para que sea calificado como tal, coordinación de las diversas entidades en territorio aragonés, fomento e investigación, etcétera. Los artículos 7 a 10 forman el tercer título, que desarrolla el Estatuto del voluntariado social, esto es, el catálogo de derechos y obligaciones tanto de los voluntarios (derechos de formación, participación, seguridad, reconocimiento y respeto, etc, y deberes de cumplir los compromisos adquiridos, confidencialidad de la información, respeto, etc.) como de las entidades colaboradoras respecto a dichos voluntarios (medios, garantías, gastos, seguros, formacion e información...). El título IV está dedicado a los programas y proyectos del voluntariado social, estableciendo qué aspectos deben recoger los programas generales y los proyectos específicos de voluntariado para poder solicitar subvenciones de la Diputación General (además el art. 12 dispone la futura elaboración de un catálogo de recursos de voluntariado social de la Comunidad Autónoma); y el título $\mathrm{V}$ delimita mínimamente las tareas de fomento y control por parte de la Diputación General de Aragón en los programas o proyectos de voluntariado social y en la participación de los aragoneses en las Entidades que lleven a cabo dichos programas. No cabe duda que la eficacia material de las intenciones descritas o prescritas en todo el articulado depende de las medidas concretas tanto administrativas como de desarrollo normativo que tome la Dipulación General, tal como le capacitan las disposiciones adicionales y finales de la ley. Y entre ellas, fundamentalmente, lo que hace a la adopeión de medidas de carácter

\section{ESTUDIOS}


presupuestario que permitan desarrollar esas competencias y llevar a cabo esos programas y proyectos, que quedan condicionados a las «posibilidades financieras» de la Administración 6 .

En todo momento, al iniciar su lectura, la Ley aragonesa parece advertir que ella se dedica únicamente a recoger y partir de un fenomeno existente socialmente de forma espontánea y libre: «El voluntariado social -dice el preámbuloconstituye, así, el concepto básico de la Ley y el punto de partida para alentar aquella corresponsabilidad asumida individualmente de forma libre y de manera desinteresada y responsable». Y al que ella, la Ley, va a ofrecer una forma de desarrollar y garantizar «el efectivo ejercicio de la solidaridad, dentro de una sociedad que necesita, cada día más, de esfuerzos altruistas, propiciando de esta forma actuaciones que contribuyan al bienestar de todos y cada uno».

Otros autores han puesto de relieve la inmensa paradoja que es el derecho, dedicándose a restringir o a canalizar la libertad precisamente para proteger 0 garantizar esa misma libertad que sólo puede garantizar regulando, es decir, limitando. Algo así se desprende de esas palabras de la Ley. Nuestro punto de vista, sin embargo, no tiene nada que ver con una propuesta totalmente antinormativa en este punto. Es más, deshacer la paradoja mencionada puede conllevar deshacer la segunda parte de la misma (la protección y la garantía de...), y puede ser positiva y necesaria una regulación jurídica o al menos una cierta atención desde la Administración hacia el fenómeno social del voluntariado. Nuestro interes estriba sencillamente en tratar de ofrecer algunas reflexiones que contribuyan a comprenderlo mejor en todas sus dimensiones e implicaciones socio-políticas. Que ayuden, aunque sea mínimamente, a discernir ese paso (que, por otro lado, es de ida y vuelta) entre el fenómeno social del voluntariado y el fenómeno del «voluntariado social» como concepto regulado jurídicamente?

(6) La Disposición Adicional 5 `ice que «La Diputación General, para la puesta en práctica de la presente Ley, dentro de sus posibilidades financieras, habilitará una dotación especiffica en los presupuestos anuales".

(7) Ya en los debates de la elaboración de la Ley aparece la discusión sobre la necesidad o no de una regulación, en una enmienda a la totalidad, que defiende que se trata de cuna normativa que no debería existir», que no precisaría una regulación expresa aunque sí medidas de promoción y ayuda por parte de la Administración. Cfr. Diario de sesiones de las Cortes de Aragón No 33 (1992), correspondiente a la sesión plenaria núm. 35, celebrada el 1 de octubre de 1992, pág. 983 . 
Por otro lado, como también advierte Angel Fernández Pampillón, «tegular jurídicamente» no tiene por qué ser sinónimo de «burocratización y rigidez». Y puede ser signo de todo lo contrario, es decir, garantía de libertad; pero también puede ser un simple instrumento de control y limitación sin más. Para ese autor, «la existencia de una regulación del voluntariado es útil» y conlleva consecuencias prácticas como son: a) «garantiza la libertad del trabajo voluntario frente a obstáculos que incluso legalmente pueden oponerse al mismo»; b) «permite el deslinde entre trabajo voluntario y asalariado«»; c) «proporciona criterios para la solución de conflictos entre los voluntarios y sus organizacionés»; d) «establece medidas públicas de apoyo al voluntariado«. De ahíque para él sea importante tratar de cuestiones jurídicas en el voluntariado ${ }^{8}$. Sin embargo, quizás tanto frente al optimismo o al pesimismo jurídico de unos u otros sea necesario mantener un cierto «optimismo escéptico o moderado» que atienda expectante a cuál va ser en realidad la utilidad de dichas regulaciones en relación al desarrollo del voluntariado social. Y que precisa reflexionar más en profundidad sobre la forma en que el derecho aborda dicha realidad, y sobre los efectos que produce esa forma de abordarlo.

El artículo 1 de la Ley del Voluntariado de Aragón dice que

«La Ley del Voluntariado Social es el conjunto de nomas que, en el marco de la accion social de la Comunidad Autónoma aragonesa, tienen por objeto regular, fomentar y promover la participación de los particulares en actuaciones definidas como propias del Voluntario Socials.

Pero, ¿qué es en realidad el «Voluntariado Social» o cuáles son esas «actuaciones definidas como propias»?. ¿Y quién dice que son «propiamente» voluntarias?: El derecho, claro.

\section{La definición social (y juridica) de la realidad}

El término «voluntariado», y el discurso que genera, puede ser un buen ejemplo de cómo la relación que los lingüistas más puros establecen entre significado y significante es una realidad social resultante, como dice Bourdieu,

(8) FERNÁNDEZ PAMPLLON, A. Cuestiones juridicas del voluntariado, op, cit, págs. 7-8. 
LA CONSTRUCCIÓN JUFIDICA DEL VOLUNTARIADO SOCIAL

de la coyuntura o encuentro entre nuestras disposiciones o habitus y las esiructuras sociales (las sanciones y las censuras del campo social) ${ }^{9}$. Lo que las palabras quieren decir es a menudo distinto de lo que queremos decir con las palabras. O dicho de una forma más sencilla, que el de «voluntariado social» es un concepto (como todo concepto, por otro lado, en mayor o menor medida) profundamente social, surgido de la práctica social.

Así parece que lo toma Fernando Aragonés cuando habla del «concepto social del voluntario» (sin duda, también, para distinguirlo del concepto jurídico) ${ }^{10}$. Lo que no aparece claro en la síntesis que hace este autor, y quedaría por ver, es cómo la delimitación conceptual es fruto de un proceso concurrente en el que intervienen distintas orientaciones practicas y desde distintas posiciones sociales. Más claramente, y tomando uno de los puntos de debate que se dan en las definiciones que presenta: por ejemplo no es lo mismo pensar (y decir) que dentro de lo que entendemos por voluntariado social estaria la Prestación Social Sustitutoria a que son obligados los objetores de conciencia o entender que dicha PSS tiene un caráctercoactivo que impide concebirla como tal voluntariado social ${ }^{11}$. Encontraramos otros ejemplos interesantes en cuanto a la posibilidad o no de recibir gratificaciones o algún tipo de remuneración, o la diferencia con otro tipo de trabajos gratuitos o prestaciones sociales; sobre la condición laboral ono del voluntario, la necesidad o no de realizar la acción voluntaria en el marco (o a través de) de una organización (reconocida o no como entidad de voluntariado), etc. Y más interesantes e importantes todavía en cuanto al papel que el voluntariado realiza o ha de realizar o los campos en los que debe moverse (más allá o más acá del Estado), porque por ejemplo, como dice Joaquín García Roca, "plantear la acción voluntaria solamente allí donde el Estado no puede o

(9) BOURDIEU, P. (1985), ¿Qué significa hablar?, Madrid, Akal.

(10) ARAGONES, F. (1986), "Apuntes teóricos sobre el voluntariado», en Varios, Voluntariado Social. Apuntes y propuestas, Madrid, Ed. Popular, págs. IIss.

(11) La ley aragonesa de voluntariado social incluye la PSS como voluntariado, a tenor de lo establecido en la Disposición Adicional $4^{*}$, que dice que «La Diputación general propondrá ante la Administración del Estado, y de acuerdo con lo establecido en la Ley 48/1984, de 26 de diciembre, reguladora de la objeción de conciencia y la prestación social sustitutoria, la participación de objetores de conciencia en sus programas de voluntariado social». Sería necesario reflexionar hasta qué punto el modelo de PSS actual concide con un modelo de Voluntariado Social, pero desde el punto de vista de la ley, todo depende de lo que ésta quiera definir como voluntariado soctal. 
no quiere entrar es el primer paso hacia la privatización o hacia el desmantelamiento del Estado Social $»^{12}$.

Es decir, que en la concurrencia o competencia entre las distintas prácticas (u orientaciones político-sociales), se va construyendo dicha realidad de «Voluntariado Social». Con la trascendencia que, tanto respecto a la orientación y definición de la política social, como a la legitimación de los discursos y la distribución de los recursos, tiene dicho proceso. Y mayor trascendencia aún cuando entra en juego el Derecho a la hora de decir qué es voluntariado y qué no. De ahí la necesidad de replantear (y replantearse como voluntarios) las implicaciones políticas de la acción voluntaria. Pero no precisamente para abandonar el voluntariado, sino para reforzarlo en su dinamismo como cauce de participación y transformación social, frente a otras fórmulas más «light» que olvidan dichas implicaciones o incluso pretenden «desnudar» al voluntariado de las mismas.

Por eso, como decíamos, «voluntariado» puede querer decir muchas cosas y englobar diferentes realidades. Desde la simple prestación gratuita o desinteresada (voluntario) hasta la participación solidaria en la satisfacción organizada de determinadas necesidades (social) se nos presenta una realidad pluridimensional en múltiples círculos concéntricos en los que se van especializando, o complicando, las características. Y puesto que la misma definición es parte de lo definido, puede parecer injusto dejar fuera de ella a determinadas realidades, o incluir a otras. Por eso se multiplican las definiciones y por eso se hace difícil, dar una definición unívoca de voluntariado en cuanto fenómeno, porque, en cuanto tal, es una realidad plural y dinámica ${ }^{13}$. ¿No es posible dar entonces una definición clara y concreta de lo que es el voluntariado social en cuanto fenómeno objetivo?. Sí, pero teniendo en cuenta el proceso en el que estanios inmersos al hacerlo, y que como tal fenómeno social, histórico, se trata de definiciones ideológicas (o utópicas) ${ }^{14}$ : es decir, de construcciones sociales.

(12) GARCIA ROCA, J. «La cuitura del voluntariado», op. cit., pág. 456.

(13) Fernando Aragonés, sin agotarlas, recoge diez definiciones, en op. cit. págs. 12 y ss. Tengamos en cuenta, ademas, que «definit» quiere decir, delimitar, establecer los fines o los límites, es decir, acotar una realidad.

(14) En el sentido mannheimniano de los términos (vid. Kan MANNHEIM, Ideología y utopia, México, Fondo de cultura económica, 1987). Por su parte, Mario Espinoza habla de alos principios ideológicos del servicio voluntariom al dar una definiciốn del misno. Cfr. Teoría y prácicica del servicio voluntario, Buenos Aires, Humanitas, 1982, pígs. 13-19. 
Para Víctor Renes, por ejemplo, las «características que conforman el perfil del voluntario, sobre las que hay un amplio consenso" son las siguientes: «desinterés, responsabilidad, sin remuneración económica, acción realizada en beneficio de la comunidad, que obedece a un programa de acción, voluntad de servir, actividad solidaria y social, su trabajo no es una ocupacion laboral habitual, es una decision responsable que proviene de un proceso de sensibilización y concienciación, respeta plenamente al individuo y puede trabajar de forma aislada, aunque por lo general actúa en grupo» ${ }^{15}$.

Ahora el problema o, mejor dicho, la discusión, vendría sobre la posible interpretación que de cada una de esas características podamos ir haciendo, con los diversos matices y preguntas que pudiéramos ir desdoblando de cada una de ellas. Lo cierto, sin embargo, es que, en este punto, al «tecoger» 0 «reconocer» esa realidad social, interviene el derecho cuando hace un retrato y definición de la misma. Dice la Ley aragonesa en su artículo $2^{2}$ :

«Se considera voluntario social, a los efectos de la presente Ley, a toda persona física que, por decisión propia, de forma desinteresada y responsable, y por motivaciones inspiradas en principios de solidaridad y participación, dedica parte de su tiempo libre a actividades de acción social, siempre que las mismas no se realicen en virtud de una relación laboral o funcionarial».

Yen el artículo $3^{\circ}$ define también como «principios básicos de actuación del voluntariado social»:

«a) La solidaridad con otras personas o grupos que se traduzca en acciones en favor de los demás o de intereses sociales colectivos que tiendan a erradicar o modilicar las causas de la necesidad o marginación.

b) La complementariedad respecto al trabajo rcalizado por los profesionales de la acción social.

c) La gratuidad, no buscando el servicio que se presta ningún beneficio

(15) RENES, V. (1989), «El voluntariado: solitaridad y particupación en la sociedad dual», en Sal Terrae vol. 77 , junio 1989/6, pág. 435 . 
económico propio.

d) El asociacionismo, llevado a cabo a través de cauces organizados de actuación.»

De manera que el voluntario lo es cuando su actuación se lleva a cabo «con arreglo a programas y proyectos promovidos por la Administración Pública o Entidades privadas sin ánimo de lucro, inscritas como tales» en el correspondiente Registro (artículo $4^{\circ}$ ). Una actividad es de voluntariado cuando se lleva a cabo en entidades de voluntariado, y para que una entidad sea de voluntariado debé organizarse de acuerdo a los criterios de la ley.

El derecho (el legislador), por lo tanto, da una definición, su definición, de voluntariado social. En cuya elaboración, sin duda, han sido tenidas en cuenta de una u otra forma las diferentes concepciones y pulsiones de las entidades y organizaciones de voluntarios; pero que es también resultado de otros intereses y concepciones ${ }^{16}$. La interpretación de dicha definición, por otro lado, queda reservada a los técnicos especializados y autorizados para ello: determinados juristas o profesionales, funcionarios o no, que cuentan con la legitimidad suficiente para poder decir qué es lo que dice el derecho.

No cabe duda, por otro lado, que la definición propuesta por la ley aragonesa, que hemos recogido, es bastante amplia y recoge, en lo esencial, los elementos fundamentales que plantean todas las definiciones. Y si tomamos la lista de «los campos a los que se dirigirán los programas de actuación del voluntariado social » que se hace en el párrafo 3 del artículo $4^{\circ}$, aparte de ser lo suficientemente amplia, recoge en último lugar la referencia a «otros colectivos», como dejando la puerta abierta a posibilidades diversas que se planteen en el curso de la acción social. Sin duda la normativa propuesta puede ser positiva en cuanto a determinados «contenidos», por decirlo de alguna manera, del concepto de voluntario social (que por su parte define toda la ley). $Y$ sin duda podríamos hacer matizaciones más concienzudas a esa afirmacion. Pero lo que nos interesa sobre todo es poner de relieve el hecho de que con ello la Administracion, el

(16) Los debates en las Cortes aragonesas para la elaboración de dicha Ley son, al fin y al cabo, toda una discusión sobre ese concepto de voluntariado. A través de los discursos de quienes intervienen en el debate podemos advertir, tras ladado y remozado, aquel que sostienen quienes reflexionan habitualmente sobre este tema, a saber: los agentes comprometidos en el campo social del voluntariado. Cfr. Diario de sesiones..., cit. págs. 981-989. 
poder público, el Estado al fin y al cabo (ya que los entes autonómicos también son Estado), esa suerte de meta-campo social o «conjunto de campos de fuerzas donde se desarrolian las luchas que tienen por objeto el monopolio de la violencia simbólica legítima ${ }^{17}$, interviene de forma directa y específica a través del derecho, el discurso del poder (simbolico) por excelencia, en la configuración del voluntario social como dicho voluntario, que es una intervención en la configuración de (una de) las formas de participación y acción social ${ }^{18}$.

\section{La eficacia simbólica de las formas juridicas}

«La realidad social es tanto la realidad propiamente dicha (la realidad-real, pudiéramos decir), cuanto la definición de dicha realidad $*^{19}$. O dicho de otro modo: la realidad no sólo es lo que es sino sobre todo lo que decimos (o decidimos expresamente) que sea. $Y$ en esa labor de definición el poder, el derecho, ocupa un lugar privilegiado. En principio todo el mundo tiene poder para decir, para definir, pero a la hora de la verdad unos tienen más capacidad para decir cómo son las cosas, más que otros, según la posición que ocupan de dominación o hegemonía (los intelectuales y famosos, por ejemplo), o según la autoridad o legitimidad para utilizar eficazmente los instrumentos simbólicos que sirven para definir, para crearoconstruir el mundo social (el lenguaje). Pero el lenguaje más importante para la definición de lo que constituye (y se convierte en) la realidad social, es el derecho, las formas y formulas del derecho, cuyo discurso posee una capacidad generativa (performativa) que va más allá del

(17) BOURDIEU,P. (1992), Réponses Pour une anthropologie réflexive, Paris, Seuil, págs. 86-87. Esa violencia simbólic a consiste en kel poder de constituir y de imponer como universal y universalmente aplicable en el resorte [ressort] de una nación, es decir en los límites de las fronteras de un país, un conjunto común de normas coercitivas». En la definición de Estado, por tanto, está incluida la noción de Derecho dado que la autoridad jurídica es al entender de Bourdieu la eforma por excelencia de la violencia simbólica legétima cuyo monopolio pertenece al Estado y que se puede servir del ejercicio de la fuerza fisica» (cf́. P. Bourdieu, «La force du Droit. Eléments pour une sociologie du champ juridigle», en Actes pour la recherche des sciences sociales $N^{\circ}$ 64/1986, pág. 3).

(18) No porque consideremos que no debe hacerlo, o cómo debe hacerlo, que sería otro tema a discutir; sino porque consideramos imprescindible caer en la cuenta de que to hace y cómo lo hace, como punto de partida indiscutible para un análisis socio-político del voluntariado.

(19) BELTRÁN, M. (1991), La realidad social, Midrid, Tecnos, pág. 164. 
mero caracter instrumental.

Desde esa perspectiva, podemos decir que el derecho crea o hace el mundo social (sin olvidar, como señala Bourdieu, que a su vez es el mundo social el que hace al derecho) ${ }^{20}$. O que la Administración (a través del derecho) lleva a cabo una tarea de construcción de la realidad social. Miguel Beltrán lo expresa claramente: «La racionalidad de la norma es impuesta a la realidad, y el orden jurídico al presunto desorden social. De esta forma se construye por la Administración la realidad social sobre la que opera. El primer paso fue delimitarla de lo que la Administración no está dispuesta a tomar en consideracion; el segundo paso es simplificarla y ordenarla, suplantando la realidad por los textos con valor jurídico; el tercer paso consistirá en intentar modificarla (en el sentido que sea) ${ }^{21}$.

En el tema que nos ocupa, al definir el voluntariado social, la norma aragonesa está acotando (construyendo o re-construyendo) un objeto concreto, una realidad, sobre la que poder operar y actuar en adelante. Desde la noma, voluntariado social es lo que dice la norma que es y no otras «realidades» por mucho que se le parezcan. Para poder considerar algo (o alguien) como voluntariado, ese algo debe reunir las condiciones y características exigidos por la noma, que es la que tiene autoridad para reconocer la «auténtica realidad»social del voluntariado e investirle o instituirle como tal. De manera que no existirán otras fómulas diferentes de voluntariado que no sean las que define la ley. No existirán al menos oficialmente.

Ese poder simbólico de nominación, o poder de actuar sobre lo real actuando sobre las representaciones de lo real, sólo existe a condición de que el propio discurso jurídico sea reconocido como tal, es decir, «en la medida en que permanece desconocida la parte más o menos grande de arbitrariedad que está en el principio de su funcionamiento» y que tiene que ver con «la creencia en la neutralidad y la autonomía de los juristas ${ }^{22}$. Es decir, que la capacidad del derecho para definir y consiguientemente construir o re-construir el mundo social no es absoluta. Se mueve también en un contexto social en lucha o

(20) BOURDIEU, P. «La force du droib», op. cit., pág. 13.

(21) BELTRÁN, M. La realidad sacial, op. cit., pág. 171. Vid. Lambién MARTÍNEZ GARCIA, J.I. (1992), La imaginación jurídica, Madrid, Debate.

(22) BOURDIEU, P. «La force du droit», op. cit., pág. 15. 
competencia, en el que nosotros podríamos, desde otros parámetros, llevar a cabo, si fuera necesario, otras formulas de voluntariado distinto. Sin embargo, es preciso reconocer la especial posición del discurso jurídico en ese contexto social, y su manera de funcionar. Su eficacia en la dominación simbólica tiene que ver con la fuerza que la forma jurídica tiene como «foma por excelencia del discurso legítimo» ${ }^{23}$.

Desde un punto de vista sociológico se ha insistido en esa eficacia simbolica del discurso o las formas del derecho. Especialmente podemos atender al análisis que del campo jurídico ha hecho el sociólogo francés Pierre Bourdieu, para comprender cómo actúa el derecho en esa labor de construcción de la realidad social ${ }^{24}$. Dicho autor ha señaladoentre los efectos (la fuerza) dela forma jurídica, tres importantes, que a su vez podemos considerar relacionados o dependientes entre sí y que podemos resumir de esta manera:

a) La universalización y generalización que impone el trabajo jurídico a través de la codificación: "mediante la sistematización y la racionalización que hace soportar a las decisiones jurídicas y a las reglas invocadas para fundarlas o justificarlas, confiere el sello de la universalidad, factor por excelencia de la eficacia simbólica, a un punto de vista sobre el mundo social del que vemos que no se opone en nada decisivo al punto de vista de los dominantes. Y mediante ello, puede conducir a la universalización práctica, es decir a la generalización en las prácticas de un modo de acción y de expresion ${ }^{25}$. Es decir, desde ese análisis, lo que es un punto de vista panticular (que no quiere decirprivado) sobre el voluntariado, se convierte en punto de vista universal de la misma realidad y conduce a la generalización del modo de actuar («universalización práctica») según el modelo que of rece dicho punto de vista.

b) Esa universalización conlleva además un efecto de normalización o naturalización que «viene a redoblar el efecto de autoridad social que ya ejercen la cultura legítima y sus detentadores para dar toda su eficacia práctica a la coacción jurídica»: «Mediante la promoción ontológica que opera transmutando

(23) Ibidem.

(24) Vid. también GARCfA, M. (1991), «Eficacia simbólica y eficacia instrumental del derecho», en El otro derecho N 7 (LLSA, Bogotá, 1991), págs. 5-27.

(25) BOURDIEU, P. «La force du droit», op. cit, pág. 16. Para estas reflexiones, ver también, del mismo autor, «La codificación», en Cosas dichass, Buenos Aires, Gedisa, 1988 . págs. 83-92. 
la regularidad (lo que se hace regularmente) en regla (lo que es de ley hacer), la nomalidad de hecho en nomalidad de derecho (...) la institución jurídica contribuye sin duda universalmente a imponer una representación de la normalidad en relación a la cuál todas las prácticas diferentes tienden a aparecer como anómicas, es decir, anormales, patologicas ${ }^{26}$. Lo normal y natural es la norma y la norma es la que dice que es lo normal (y natural). El voluntariado recogido en la norma es el normal, y otras posibilidades no son sino exirañas anomalías o fómulas extravagantes (cuando no patologicas) de funcionamiento. Tal es la manera de «funcionar» del discurso jurídico en sus efectos, sobre todo si tenemos en cuenta el «reconocimiento público de normalidad» que conlleva el carácter oficial de las normas jurídicas.

c) En tercer lugar, la homologación que se traduce «en la objetividad de una regla o de un reglamento escrito»: «a la manera de la objetivación de un código explícito del código práctico que permite a los diferentes locutores asociar el mismo sentido al mismo sonido percibido y el mismo sonido al mismo sentido concebido, la explicitación de los principios hace posible la verificacion explícita del consenso sobre los principios del consenso (o del disenso)». Esa homologación «hace posible una forma de racionalización, entendida, con Max Weber, como previsibilidad y calculabilidad». De forma que los agentes que se encuentran atrapados en una situación codificada «saben que pueden contar con una norma coherente y sin escapatoria, y por lo tanto calcular y prever tanto las consecuencias de la obediencia a la regla como los efectos de la transgresión». Pero esa homologación sólo tiene sentido para aquellos «que están de lleno en el universo reglado del formalismo jurídico», es decir, los profesionales oespecialistas jurídicos. Los demás, dice Bourdieu, están avocados a soportar la violencia simbólica del derecho, la fuerza de la forma ${ }^{27}$.

\section{4. «El Estado voluntario»}

Apuntábamos al principio la importancia que el fenómeno del voluntariado ha cobrado en el esfuerzo por reflexionar y re-presentar la dinámica de los diferentes sectores y agentes socioeconómicos en el conjunto del tejido social,

(26) BOURDIEU, P. «la force du droit», op. cit, pág. 16.

(27) Ibid., págs. 17-18. 
y el papel que éstos juegan. De forma tópica esa representación suele hacerse en torno al binomio Estado-Sociedad civil. Sin embargo, los autores han puesto de relieve la incapacidad de dicho modelo para dar cuenta de la pluralidad de agentes existentes y actuantes en la sociedad, y han propuesto otro tipo de lecturas tripartitas (mercado, sector público y tercer sector) o cuatripartitas (grupos de carácter primario, mercado, relaciones institucionales y entidades voluntarias y estado $)^{28}$. De fondo, por otro lado, late en dichos análisis el tema de la crisis del Estado de Bienestar y la nueva situación de las redes de solidaridad social, que desborda con mucho estas breves reflexiones.

Lo que sí queremos recalcares el hechode que los diferentes autores subrayan el carácter relativo (o arbitrario, en el buen sentido de la palabra) ${ }^{29}$ de los diferentes esquemas (binario, tripartito o cuatripartito), en su esfuerzo por dar razón de la dinámica social. Y el carácter relacional de los mismos, en el sentido de que los diferentes sectores se encuentran inter-relacionados, formando parte de un mismo sistema social. Lo cual es importante tener en cuenta para no caer en el error de considerar voluntariado y Estado (por ejemplo) como plataformas aisladas. Más bien, podríamos decir, cuando se habla de la relación entre Sociedad y Estado (y podríamos extenderlo tanto a las propuestas tripartita como cuatripartita) hay que pensar que se trata de una relación en la Sociedad y/o en el Estado. Ya que si bien podemos pensar en la existencia de zonas netas o auténticamente de poder público, y zonas exclusivamente privadas, la realidad más bien se nos muestra en tonos confusos, en zonas grises donde los perfiles de las diferentes entidades o sectores se diluyen y desdibujan. Por otro lado, la diferencia entre lo público y lo privado no necesariamente se corresponde con la diferencia entre el Estado y otro tipo de campos sociales. Esa diferencia se reproduce también en el mercado, y en las redes de solida-

(28) Para la propuesta tripartita yid. Ugo ASCOLI, «Estado de bienestar y acción voluntaria», en Revista española de investigaciones sociológicas №37 (1987), págs. 119-162; Id., «Voluntariado organizado y sistema público de Welfare: Potencialidad y límites de una cooperación», en Documentación social N$^{9} 71$ (1988), págs. 183-202. La propuesta cuatripartita es defendida por Demetrio CASADO. «Las organizaciones sociovoluntarias», en Varios, Organizaciones voluntarias e intervención social, Madrid, Acebo, 1989, págs. $17 \mathrm{ss}$, que además hace una sintesis de las diferentes lecturas. Sobre este tema ver también Joaquín GARCIA ROCA, Público y privado en la acción social, Madrid, Ed. Popular, 1992; Varios, El voluntariado en la acción sociocultural, Madrid, Ed. Popular, 1990.

(29) En cuanto construcciones sociales, podríamos repetir. 
ridad primaria, etc. Esa interrelación no quiere decir que no vayan a existir conflictos. Todo lo contrario: si hay conflictos es precisamente porque existe esa interrelación. La intervención (o no-intervención) desde diferentes perspectivas en una misma realidad social, provoca esos mismos conflictos. Y de ahí la necesidad de repensar el carácter socio-político del voluntariado, más allá de su consideración como una experiencia privada y totalmente al margen de otros sectores sociales.

Y más todavía cuando el Estado, el sector público, precisamente interviene con toda la potencia simbólica del discurso jurídico para definir y regular ese sectór reservado al voluntariado. El Estado se hace voluntario, por decirlo de alguna manera, y decide que el voluntariado ha de ser desde entonces tal como él lo es. Se produce, por lo tanto, una legítima, y tal vez necesaria, intervención del sector público en la acción social a través de otros sectores (no menos públicos, pero diferentes) como los que conforman las distintas organizaciones y entidades de voluntariado social que es preciso tener en cuenta. Sobre todo para saber sus posibles «efectos» en el concurso de la acción y la participación social. Una intervención que podemos advertir, en nuestro caso, en la Ley aragonesa del voluntariado social.

La primera contribución, que se da al nivel más propiamente simbolico, de la Ley, es la legitimación de un determinado tipo de voluntariado social (y la consiguiente deslegitimación de los demás) ${ }^{30}$ : La legitimación de aquel voluntariado que «cumple» las condiciones recogidas en la ley.

Pero, sin duda, no es está la única contribución importante, y existen otras también necesarias: Así, el establecimiento de una serie de medidas de apoyo al voluntariado que «promete» $1 \mathrm{~L}$ Ley ${ }^{31}$; o el establecimiento de un Estatuto del

(30) Y por lo tanto, como señalábamos al principio, la legitimación de unos determinados modelos de organización, trabajo y participación social.

(31) Por ejemplo, dice el artículo 13 de la Ley que «La Comunidad Autónoma prestará el apoyo necesario a los voluntarios y a las Entidades colaboradoras de voluntariado social públicas o privadas. A tal efecto, la Diputación general regulará un sistema de subvenciones y conciertos destinados a cubrir, en función de las disponibilidades presupuestarias, la totalidad o parte de los gastos ocasionados en la ejecución de un proyecto de voluntariado social». Y en el párrafo $2^{\circ}$ del mismo artículo dice que «la Diputación general establecerá mecanismos de asistencia técnica, organizará cursos de formación y campañas de información y extensión del voluntariado social, y adoptará cuantas medidas de apoyo y de fomento se deriveno de la Ley. También en las Disposiciones Adicionales habla de la posibilidad de «adoptar medidas de 
yoluntariado social que garantice una serie de derechos y obligaciones, tanto para el voluntario como para la entidad colaboradora, que justifiquen su consideracion (en el marco de la Ley) como voluntariado social ${ }^{32}$. La Comunidad Autónoma abraza así el conjunto de los recursos sociales llevados a cabo por las diferentes entidades de Voluntariado Social reconocidas como tales, promoviendo su tarea. Y se otorga a la Diputación General las correspondientes competencias de fomento y control de dichos recursos ${ }^{33}$.

Indudablemente, es necesario, que se lleve a cabo un control para comprobar que los recursos materiales destinados a una finalidad concreta se dedican a esa finalidad y no a otras diferentes. Se supone que ésa es (o debería ser) una de las bases del funcionamiento de la gestión de la Administración pública. De la misma forma que es necesario un control para que el voluntario social no se convierta en una vía barata de suplir deteminados puestos de trabajo, o las entidades puedan aprovecharse injustamente de su dedicación gratuita. Y más cuando esos voluntarios (paradojas de la vida) lo son obligados, como es el caso de los objetores de conciencia que realizan la Prestación Social ${ }^{34}$.

Pero más allá de esa perspectiva, o tratando de llevar un poco más lejos la reflexión, podemos decirque la Ley aragonesa del voluntariado supone también para la Administración un importante instrumento de control social desde la intervención (más indirecta, pero también directa) a través del voluntariado, en la acción social; 0 de control de la acción social. Por ejemplo: ¿Se reconocería como entidad de voluntariado, o programa de voluntariado a aquella que

apoyo a programas de cooperación estatal o internacional» en determinadas condiciones (D.A. $\left.1^{2}\right)$; de fomentar sla existencia de actuaciones propias de voluntario mediante la realización, en su caso, de experiencias piloto» (D.A. $2^{3}$ ); o de adoptar las medidas oportunas "para incluir en la fonmación de los profesionales sociales un espacio dedicado al voluntariado social y los diversos medios de coordinación y colaboración» (D.A. $3^{3}$ ).

(32) Título III de la Ley, artículos 7 a 9.

(33) Ya hemos hecho referencia al art. 13 de la Ley dedicado al fomento. Por su parte, el artículo 14 lo hace expresamente respecto al control: «Las entidades colaboradoras de voluntariado social que reciban ayudas de la Diputación General están obligadas a remitir al Departamento de Sanidad, Bienestar Social y Trabajo, además del programa general de voluntariado social y de los proyectos mencionados en el artículo 11 de esta Ley, una Memoria justificativa que acredite que las ayudas o subvenciones recibidas para la ejecución de un proyecto de voluntariado social han sido destinadas a la finalidad que motivó su concesión».

(34) Como hemos visto, de acuerdo a la D, A, 43. 
proyectara realizar la asistencia y promoción de los extranjeros que se encuentran en situación irregular (indocumentados) en nuestro país, a tenor de la política gubernamental en este tema? ${ }^{35}$. Probablemente no, podemos pensar. La Ley sirve así como instrumento de control en la acción social, a partir de lo que la norma considera legitimado para ser tomado como voluntariado.

De hecho, el tema del control que la ley ejerce sobre los proyectos de voluntariado social fue uno de los principales motivos de discusión en la elaboración de la Ley, como se advierte en el Diario de sesiones de las Cortes aragonesas que recoge la llevada a cabo el jueves 1 de octubre de 1992. El debate fundamental estribaba precisamente en la excesiva capacidad de control que la Ley otorgaba a la Administración, y alguna de sus señonías interpretaba la voluntad legislativa con la de «ejercer ciertos mecanismos de control en relación con las asociaciones de voluntariado social». Es decir, que se deducía de la Ley un instrumento de control más que de fomento, tanto por las atribuciones específicas que en cuanto a fiscalización, Registro de entidades, control de subvenciones, programas de actuación, etc., que hace la norma, como por aquellas que no hace expresamente, al no «fijar con claridad cuáles deberían ser exclusivamente las actuaciones de los poderes públicos en esta materia» ${ }^{36}$,

No es absurdo, por tanto, aunque con todas las matizaciones que se quieran, hablar de esta Ley también como un formula de control de la acción social, mediante la que la Administración interviene en esa suerte de participación en dicha acción, que es el voluntariado ${ }^{37}$.

\section{A modo de conclusión: las implicaciones socio políticas del voluntariado social}

En las reflexiones precedentes se ha insistido en la necesidad de tomar en cuenta la implicaciones sociopolíticas de la acción voluntaria, y quistéramos, para acabar, insistir un poco más en ese tema que, por otro lado, creemos se

(35) Extranjeros y refugiados es uno de los campos recogidos expresamente como objetivo de los programas de actuación de voluntariado social (Art. 3.3,j).

(36) Diario de sesiones..., cit., pág. 983.

(37) De hecho toda norma, en cierta manera, es una forma de control, a la luz de las reflexiones anterionnente realizadas sobre su eficacia simbólica. Pero no todos los controles se realizan en la misma manera o parten de un mismo punto de vista.

\section{ESTUDIOS}


desprende de la lectura que hemos hecho de la Ley.

La consabida crisis de legitimación de los cauces ordinarios de participación política (los partidos) como simples máquinas de acceso al poder, y el auge de lo que se ha conocido como nuevos movimientos sociales, en el marco de lo que se ha denominado como neocorporatismo o sociedad corporativa, ha empujado hacia la consideración de nuevas formas de trabajo y participación en distintos movimientos sociales, organizaciones no-gubernamentales, entidades de acción social, colectivos de solidaridad, etc. Sin embargo, se ha tendido a calificar esa nueva participación (en la que entra de lleno el voluntariado social), como una fómula no política, quizás para diferenciarla de las fórmulas clásicas de consideración de la política. Y ello no sólo desde sectores que se pretenđen apolíticos, que quieren llevar a cabo su trabajo «sin entrar en política»; sino también desde los propios sectores pretendidamente políticos, que quieren llevar a cabo su tarea política sin la intromisión de otros intereses corporativos que no sean los que ellos defienden (suponiendo que ellos defienden los intereses generales). Dos perspectivas que de fondo tienen en común un mismo punto de vista: el que sostiene la ideología de la neutralidad ideológica, o por decirlo de otra manera: la concepción política de la no-política.

Frente a tal concepción, es preciso, por todo lo dicho hasta ahora, recuperar la conciencia política del voluntariado social y reflexionar sobre las dimensiones auténticamente políticas de dicho voluntariado como esa «nueva» forma de participación y acción en la sociedad actual que además quiere hacerse transformadora. Precisamente porque se trata de una forma alternativa de entender la política (como poder, como participación, como posible y como pública), que puede ayudar a construir lo que otros han llamado, con palabras de Péguy, «la política como organización sistemática de la caridad ${ }^{38}$.

Pero esa reflexión deben llevarla a cabo los propios voluntarios en el marco de sus programas de voluntariado. como paso básico para replantear seriamente qué tipo de sociedad se quiere, y como queremos que funcione, ya que al parecer el voluntariado se ha convertido en una pieza clave de ese funcionamiento. Repolitizando la acción voluntaria no en el sentido clásico y desgastado que le cubre con una barniz ideológico simplemente, sino en el sentido de esa «cultura del voluntariado» de sólidas convicciones que ayude a «salir del universo

(38) DIAZ, C. (1992), La política como justicia y pudor, Móstoles, Ediciones Madre Tierra. 
utilitario y de sus provisiones», $y$ «desactiva la violencia fundamental que pesa sobre nuestro tiempo: la indiferencia y la sinrazon $»^{39}$. Desde allí podemos sumamos a la creación de «zonas liberadas», en palabras de José María Mardones ${ }^{40}$, frente al nuevo triunfo del neoconservadurismo actual (que por su parte también quiere adueñarse del voluntariado), que contribuyan a hacer de la nuestra toda una «sociedad liberada».

Saber es poder. Así que saber cómo el derecho «construye» una determinada forma de voluntariado social, también, creemos, es un paso importante para llevar a cabo esa reflexión que empuje a la transformación.

(39) GARCfA ROCA, J. «La cultura del volunariadom, op. cit., pág. 449. Que es una cultura del conflicto y de la marginalidad, de la comunicación y de la vulnerabilidad.

(40) MARDONES, J.M. (199/), Postmodemidad y neoconservadurismo, Estella, Ed. Verbo divino, págs. 259-275. 